\title{
La antropología cultural en su relación con la criminología
}

\section{LA PALABRA CRIMEN Y SU USO EN LENGUA ESPAÑOLA}

Aunque por los años de 1729 y en una obra tan docta como el llamado Diccionario de Autoridades de la lengua, se diga que la palabra «crimen» es «puramente latina», su uso en castellano tiene gran abolengo. El Diccionario mismo lo acredita con ejemplos sacados de textos de teólogos y juristas del Siglo de Oro ${ }^{1}$. Pero como se indica en otros diccionarios también autorizados y modernos ${ }^{2}$, se halla ya utilizada por Gonzalo de Berceo, con la acepción de calumnia o falso testimonio, dos veces: «Levantaronli crimenes los torpes fallecido», dice una en los Milagros de Santa Maria; y en otro pasaje de los mismos se lee, «Non me levantassedes crimen de falsedad» ${ }^{3}$. Con acepción de un tipo específico de pecado la usa el mismo, en la Vida de Santo Domingo («pecado criminal»), poniéndola en boca del santo al hablar con Don García de Nájera, rey de Navarra 4 .

En la obra del arcipreste de Hita se documenta «criminal», como adjetivo ${ }^{5}$, «creminal»y, en tercer término, «encriminal» ${ }^{6}$.

En textos del siglo XV se encuentra una forma plural, latinizante: la de «crimines». Así, en La Celestina y en Hernando del Pulgar '. Más tarde, el uso se documenta de modo abundantísimo. Cervantes usa «criminal» en

1 Diccionario de la lengua castellana (Madrid, 1729), II, p. 659, b. Con ejemplos de uso en textos de Nebrija, Navarrete, La Puente, etc.

2 J. CoRominas, Diccionario crítico etimológico de la lengua castellana (Madrid, 1954), I, p. 942 a.

3 Los dos en Rufino LANCHETAS, Gramática y vocabulario de las obras de Gonzalo de Berceo (Madrid, 1900), p. 259.

4 Poetas castellanos anteriores al siglo XV, B.A.E., LVII, p. 44a (estrofa 137).

5 Libro de Buen Amor, ed. de Julio CEJADOR, I (Madrid, 1913), pp. 132 (estrofa 357 b), 133 (estrofa $360 \mathrm{~d}$ ), pleito criminal.

6 Idem, ed. cit. I, p. 133 (estrofa 358 b). Lectura de José María AGUADo, Glosario sobre Juan Ruiz, poeta castellano del siglo XIV (Madrid, 1929), p. 312.

7 Corominas, op. cit., loc. cit. 
El Licenciado Vidriera ${ }^{8}$; Lope, «crimen», «criminal» y «criminalmente» varias veces ${ }^{9}$. La palabra, por otra parte, así como las derivadas, se halla en los léxicos y diccionarios de los siglos XVI y XVII ${ }^{10}$. Alguno da aclaraciones sustanciales sobre su uso y etimología. Así el Tesoro... de Covarrubias, donde se lee que es «el pecado grave. Lat. crimen, minis. Díxose del verbo griego crino, iudico, porque deve ser juzgado, conviene a saber castigado severamente; dize más que delicto. Nam iurisconsulti inter crimen et delictum distinguunt perspicuitatis studio, ita ut criminis nomine capitalis fraus intelligatur, veluti caedes, adulterium, etc., delicti vero privata noxia, ut furtum, iniuria. Crimen laesae maiestatis el que se comete contra Dios o contra el rey" ". Sin embargo, los usos comunes, en español, son más limitados que en latín, porque la palabra no se emplea con las acepciones de motivo, pretexto, reproche o falta de alguna cosa. Tampoco se utiliza para designar al acusado o criminal, como se hace en aquel idioma.

En punto a la naturaleza de los llamados crímenes advertimos que, en el mundo clásico, una parte considerable de ellos eran de carácter religioso, ofendían a la religión en conjunto y a los dioses individualmente considerados. Su castigo o expiación tenía este mismo carácter religioso. Dejando a un lado esta clase de crímenes contra los dioses, de los que hay ejemplos abundantes estudiados, nos resulta más difícil de comprender la idea de que los dioses mismos puedan ser autores de hechos que se consideran criminales. Pero Ovidio habla de sus adulterios como de otros tantos crimina caelestia.

\section{RELATIVISMO EN LA CONCEPTUACIÓN DEL CRIMEN}

Esta ligerísima exploración lingüística nos hace ver la complejidad del uso de la palabra, su trasfondo religioso y lo difícil que resulta aceptar las definiciones absolutas de la misma, incluso las hechas por hombres de pensamiento robusto, bastante modernamente.

8 Novelas exemplares (facsímil de la ed. Madrid, 1613, fol. 121 r. «causa criminal»). Carlos Fernández GOMEZ, Vocabulario de Cervantes (Madrid, 1962), p. 267 b.

9 Carlos Fernindez Gomez, Vocabulario completo de Lope de Vega (Madrid, 1971), I, p. 723.

10 Samuel Gill GayA, Tesoro lexicográfico, $1492-1726$ (Madrid, s.a.), fascículo III, p. $667 \mathrm{c}$.

1 Sebastián de Covarrubias, Tesoro de la lengua castellana o española, edición de Martín de Riquer (Barcelona, 1943), p. 370 b. 
Dentro de estas definiciones pueden incluirse las que se deben a Durkheim, que se refirió en términos genéricos a un «tipo social» que en «determinada sociedad» representa a las conciencias sanas, y al que ofenden determinados actos, que serían, precisamente, los crimenes desde el punto de vista colectivo ${ }^{12}$. Ya poco después de escrito esto se señaló lo problemático de la serie de afirmaciones citadas ${ }^{13}$. Podría añadirse que es también arriesgado el aplicar criterios y expresiones sacados de la Medicina y de la Patología a la vida social.

Sin entrar ahora en la discusión acerca de si hay hechos universalmente castigados como crímenes, en la que el mismo Durkheim se enfrentó con Garofalo ${ }^{14}$, y en la definición del «delito natural» de éste, hay que reconocer que la casuística, en el ámbito de la Historia y de la Antropología, parece que da a entender que el concepto social del crimen es mucho menos homogéneo de lo que han afirmado algunos sociólogos y criminalistas y que, hoy, podemos estar más cerca de Voltaire, cuando se refirió a la existencia de crímenes y delitos «de temps et de lieu» y cuando sostuvo también que «chaque pays a ses impertinences legales, et ses délits» ${ }^{15}$.

El ejemplo que ilustra, en primer lugar, afirmación semejante es el que sigue. Un romano mata, en Egipto, a un gato «consagrado» y el pueblo furioso le castiga como sacrílego haciendo de él trozos. Si le hubieran juzgado jueces, con sentido común - añade-, le habrían condenado a pedir perdón a los egipcios y a los gatos, y a pagar una multa, sea en dinero, sea en ratones.

Dejando bromas aparte, es claro que, en tiempos muy recientes, las naciones que han poseído grandes imperios coloniales se han encarado de modo continuo con problemas graves cuando - por ejemplo- sus magistrados y jueces rechazaban denuncias por crimen de magia o hechicería ${ }^{16}$. Éstas se aceptaban, sin embargo, en sus propios países aún en el siglo XVII y dieron lugar a procesos y condenas de miles de personas durante los siglos XIV, XV y XVI y el «Derecho» en torno se codificó, como es sobradamente conocido, en obras especiales: el Malleus maleficorum por

12 Véanse, por ejemplo, las páginas que dedica al crimen en La división del trabajo social, traducción de Carlos G. Posada (Madrid, 1928), pp. 83-129. 36.

13 J. MASwell, Le concept social du crime. Son évolution (Paris, 1914), pp. 35 -

14 La Criminología. Estudio sobre la naturaleza del crimen y teoría de la penalidad, traducción de Pedro Borrajo (Madrid, 1912), pp. 1-54.

15 Artículo «Crimes et délits» en el Dictionnaire philosophique (Paris, 1819), II, pp. 387-393.

16 Godfrey y Monica WILSON, The analysis of Social change based on observations in Central Africa (Cambridge, 1945), pp. 15, 36, 72-73, etc. 
ejemplo, que tuvo vigencia hasta mucho después de que se publicara la primera edición ${ }^{17}$.

Una conciencia que podía considerarse entonces como «sana» y «normal» dentro de un «tipo de sociedad» aceptaba esto, igual que lo hacían juristas, teólogos y hombres de gran erudición y saber ${ }^{18}$.

Con respecto a las penas observamos cambios similares. Muchas, como la de la hoguera misma, se han suprimido. Otras se aceptan en ciertos países y en otros no, como la misma de muerte. Resultaría hoy también incongruente levantar causas criminales a animales u objetos inanimados y condenarlos, cosa que se ha hecho en distintos países durante siglos ${ }^{19}$ y de la que el mismo Platón habla en Las Leyes como algo normal ${ }^{20}$.

\section{VARIACIONES}

Algunos de los ejemplos aducidos bastarían para hacer ver que hay un nexo entre el concepto variable del crimen y determinadas concepciones culturales también variables: en efecto, aquel concepto cambia según pueblos, civilizaciones, creencias y convicciones morales. La consideración de ello podría llevarnos a profesar un relativismo que a algunos les parecerá tan peligroso o más que dogmatismos absolutos como los antiguos.

Pero desde el punto de vista del antropólogo cultural no hay más remedio que aceptar que las ideas acerca de lo que es crimen son de las más importantes para definir una cultura dada y conciernen a una parte básica de todas las culturas: su sistema legal, sus leyes. Por lo tanto, también su Ética.

Acerca de esto, bueno será recordar también ahora cómo cierto literato de fines del siglo pasado (Samuel Butler) escribió un relato novelado, en que describía un extraño país, donde el sistema de valores era tan diferente

17 A 9 de diciembre de 1484 el papa Inocencio VIII promulga la bula Summis desiderantes. Ésta suele encabezar las ediciones numerosas que se hicieron de la obra de los inquisidores alemanes J. Sprenger y $\mathrm{H}$. Institor, Malleus Maleficarum, que con otras se imprime poniendo el título en masculino (es decir, Maleficorum). La primera edición es de Colonia, 1489. Luego hay muchísimas, hasta el siglo XVII. En el siglo XX se han hecho traducciones con fines muy especiales y discutibles.

18 Por ejemplo, el padre Martín del Río o Jean Bodin. Lo cual no quiere decir que otros ingenios se burlaran ya de modo gracioso de estas creencias. Así Cervantes en el Coloquio de los perros. 1892).

19 Carlo d'AdDosio, Bestie delinquenti. Con prefazione di Ruggero Bonghi (Napoli, 20 Leges, IX, 873, E-874 A. 
a los del resto del mundo, que en él, a aquellos que habían cometido un hurto o hecho similar, los atendían y cuidaban como se cuida en los países conocidos a los enfermos... mientras que a los enfermos mismos les metían en la cárcel ${ }^{21}$. Esto es deliberadamente inverosímil, pero de modo sorprendente nos acerca a ideas que en nuestro tiempo cunden, como es la de considerar que gran parte de los crímenes y delitos son más bien del dominio del psicopatólogo y el psiquiatra que del penalista y de la justicia. La misma tesis de la existencia de tipos humanos "criminales natos» abrió ese horizonte hasta cierto punto, aunque haya sido rechazada por muchos ${ }^{22}$. Por otra parte, el rechazo no quita para que, con menos fijeza o determinación, se vea que hay cantidad considerable de criminales habituales de prisiones con diferentes rasgos patológicos que no corresponden a un «tipo» ${ }^{23}$, pero que expresan debilidades psíquicas y orgánicas sin cuento.

Si empezamos nuestra averiguación comparativa en el ámbito de los pueblos antiguos nos encontramos también con que hombres de Ciencias, antiguos asimismo, se refieren a distintas formas de calificar los crímenes y de establecer penas que caracterizaban a dichos pueblos. Puede pensarse, en principio, que cuando el mayor de los sofistas, Protágoras, realizó y mandó realizar averiguaciones acerca de los usos y costumbres de distintos pueblos, ya halló variaciones en el concepto respecto a lo que es bueno y malo (justo e injusto). Existe, en efecto, un corto escrito, que parece haber sido inspirado por él, conocido bajo el nombre de Dialexeis, que en su primera parte expone cómo los conceptos de «bueno» y «malo» son cambiables según los pueblos y pone ejemplos de esto, examinando las prácticas y las ideas de atenienses y lacedemonios en primer lugar. Pero todavía hay más: una sección acerca de lo que es justo o injusto para diferentes pueblos ${ }^{24}$. No se puede llegar a más, que yo sepa. Más adelante se recordará cómo en otros autores antiguos, historiadores y geógrafos, se pueden reunir materiales de gran valor, acerca de los distintos juicios que tenían pueblos diferentes respecto a crímenes propiamente dichos y penas, y sobre el juicio que esto podía merecer a un griego o un latino. A este propósito conviene recordar primero cómo Nietzsche, en el parágrafo 43 del libro primero de La Gaya Ciencia, sostiene que las leyes penales de los pueblos

21 Me refiero a Irewhon novela que apareció en 1872.

22 La tesis defendida por Lombroso, que seguía en algo una tradición de los fisionomistas italianos. Véase la nota 26.

23 Muy antiguos son ya los estudios que hay acerca de los rasgos patológicos de los presos de ciertas cárceles y presidios. Por ejemplo, de Emile LAURENT, Les babitués des prisons de Paris. Étude d'Antbropologie et de Psychologie criminelles (Paris, 1890).

24 El texto está publicado por Hermann Diels, Die Fragmente der Vorsokratiker, ed. Walther Kranz (Dublín-Zürich, 1970), II, pp. 405-416. 
no dan la expresión de su carácter, sino tan sólo lo que les parece anormal, extraño, monstruoso y ajeno. Recuerdo como ejemplo que para los wahabíes no hay más que dos pecados mortales: tener dios distinto al suyo y fumar. Un viajero pregunta a un hombre de autoridad entre ellos qué piensa del asesinato y del adulterio y éste contesta diciendo que Dios es misericordioso.

Cabría preguntarse si, precisamente, lo que parece extraño y ajeno a un pueblo no será algo de lo que más contribuye a caracterizar al pueblo mismo. Pero, sin embargo, hay que reconocer que en los tratados clásicos de Antropología, desde el de Tylor a los de Kroeber y otros de nuestros días, no se da cabida a la idea de que el concepto que tienen los pueblos de lo que es crimen sirve para definirlos. Esto me choca porque, por otra parte, los antropólogos criminales, desde un principio, echaron mano de la Antropología cultural y social, aunque fuera de modo vago e impreciso, para fijar algunos rasgos de los criminales y definir la naturaleza de ciertos crímenes. Así, por ejemplo, Lombroso defendió la tesis de que el criminal, en esencia, era un hombre dominado por el atavismo o la tendencia a mantener formas de vida y usos de otros tiempos o parecidos a los de los primitivos actuales ${ }^{25}$. Podía encontrar cierto apoyo para defender esto en lo que cabe, por ejemplo, del Arte criminal, que estudió en las prisiones, y en expresiones de él, como el tatuaje. También en algunas pruebas y ritos como aquellos a los que se sometía a los miembros de la "Camorra». Otros han defendido tesis parecidas, utilizando comparaciones bastante discutibles. Así, por ejemplo, Alfredo Niceforo, en un importante estudio acerca de la Italia meridional y los problemas que presentaba a fines del siglo XIX, sostenía que, en conjunto, era país dominado también por el atavismo, que no había sabido sacudir viejas lacras de origen bispánico o arábigo, y sobre la «Camorra» misma decía que representaba uno de estos atavismos, puesto que correspondía al «clan salvaje». Por otra parte, establecía la existencia de algo que denominaba «delito bárbaro» (antiguo) frente a otro que podría llamarse el delito moderno ${ }^{26}$.

Podemos observar que, con relación al uso del tatuaje, es público que a fines del siglo XIX fue practicado por especialistas en países como Estados Unidos e Inglaterra, dándosele significados náuticos, militares, patrióticos

25 Lombroso, L'bomme criminel (Paris, 1895), I, pp. 35-91, toda una parte sobre el crimen en pueblos primitivos. Sobre arte e industria, pp. 546-556. Sobre la fisionomía, pp. 220-263.

26 A. Niceforo, L'Italia barbara contemporanea (Studi ed appunti) (Milán-Palermo, 1989), pp. 27-60 en especial. S. Sighele se refirió, por su parte, a una «criminalità atavica» y a otra «evolutiva». 
y románticos, y en clases pudientes ${ }^{27}$. Con respecto al concepto de «clan salvaje» hay que decir que es impreciso. Clan se usa en términos generales para designar al grupo que desciende de un antepasado común y por línea masculina en las formas más conocidas. La "Camorra" es algo que, aunque se puede apoyar en el parentesco, tiene otros fundamentos más complejos y ámbitos de acción que la aproximan a otras asociaciones criminales ${ }^{28}$.

\section{EJEMPLOS DE ÉSTAS}

La utilización, pues, de datos comparativos ha de llevarse a cabo atendiendo a criterios cualitativos y cuantitativos más ajustados, para que sea útil. Hoy es tarea más bien laboriosa que difícil.

En relación con lo que desde el punto de vista del antropólogo social puede interesar más, para determinar lo que se considera crimen hay varias cuestiones que son fundamentales. En primer término, y como va dicho, se ha de establecer un apartado enorme con los que se han considerado crímenes religiosos, en sociedades con religiones distintas y en las que incluso se acusó y condenó por crimen o delito de impiedad a hombres que eran piadosos, dentro del sistema de creencias comunes. Tal fue el caso de Sócrates. Hubo otros que podían haber sido y que acaso fueron acusados de impiedad con más motivo. Por ejemplo, Protágoras ${ }^{29}$. En todo caso, el crimen, con la correspondiente pena capital, de carácter religioso es algo de inmenso significado histórico, pero que queda fuera de toda praxis, refiriéndose incluso a tiempos cercanos al nuestro. Hoy corre en lengua castellana la expresión de «cuento de brujas», para referirse a algo que es, a la vez, increíble y ridículo: pero persecuciones terribles hacia ellas se han dado muy tarde y en países que no eran católicos precisamente, como se ve por el proceso de las brujas de Salem (1692) y otros. Los artistas de época ilustrada, con Goya en cabeza, hicieron sátira genial de la creencia, que, según va dicho, ha sido objeto de enfoques y tratamientos contradictorios. Lo que en un momento se puede penar con la hoguera por otro

27 Artículo «Tatoo», The new Encyclopaedia Britannica (15.` edición, Chicago, 1986), $\mathrm{XI}$, p. $578, \mathrm{~b}$.

28 Niceforo, op. cit., pp. 57-60 sobre la «Camorra». Pero la conexión con el sistema penitenciario, la ciudad, los vínculos de distintas clases separan este tipo de asociación de un «clan», que se funda, por encima de todo, en determinadas reglas de parentesco.

29 Las formas en la fórmula de la acusación difieren ligeramente en PLATÓN, Apol., 24 b-c y Jenofonte, Mem. I, 1. En su relación con Protágoras hay muchos eruditos que estiman que su proceso y acusación, también en Atenas, conocido por textos de Diógenes Laercio, IX (8), 52, es invención de escritores tardíos. 
lado resulta objeto de burlas e ironías. En 1613 publica Cervantes El coloquio de los perros y en esa misma época salían ediciones del Malleus... Entre la burla cervantina y el terrible código no parece que hay relación posible ${ }^{30} \mathrm{y}$, sin embargo, el tiempo los une.

De modo parecido observamos que hay un castigo, que difiere mucho del concepto ridículo que corre a la vez, en relación con los que en la España del siglo XVII se llamaban «arisméticos» o «aritméticos», es decir, los homosexuales que seguían su instinto.

En la correspondencia de los padres jesuitas, que se fecha entre 1634 y 1648, publicada en el Memorial histórico español, se encuentran bastantes cartas que dan idea de los "crímenes» que se castigaban con la hoguera ${ }^{31}$. Entre ellos estaba la sodomía. A los que la practicaban (que al parecer eran bastantes pese al peligro), por otra parte, se les tomaba a chirigota. Baste con recordar el entremés de Quiñones de Benavente, para ver que también eran objeto de burlas ${ }^{32}$.

El mismo hecho puede tener dos formas de ser enjuiciado. Hoy, una puede subsistir y otra ha podido desaparecer. Pero aún ha cabido la posibilidad de una tercera posición que, comparada con éstas, parecerá aún más sorprendente. Plutarco, muy al comienzo de la vida de Solón (es decir, uno de los siete sabios de Grecia, considerado como el arquetipo del legislador), dice que éste promulgó una ley prohibiendo a los esclavos tener relaciones homosexuales porque las consideraba superiores a su estado y propias sólo de gente honorable. Para sostener esto se fundaba en un amor juvenil que él mismo había tenido ${ }^{33}$. Cuesta aceptar -insisto- un relativismo cultural absoluto, pero está - sin duda - más cerca de lo cierto que la tesis de que existe un «delito natural» en términos absolutos.

Podría parecernos que el parricidio daría la prueba de que hay delitos para todos los pueblos, considerando muchos casos y ejemplos: pero también existen otros, conocidos y reunidos hace tiempo, de grupos humanos que

30 Tengo a la vista una edición del Malleus... de Frankfürt, 1600 y otra de Lyon, de 1614. El texto de Cervantes fue comentado de modo excelente por Don Agustín G. de AMEzúa, en su edición, en que va con El casamiento engañoso (Madrid, 1912).

31 «Cartas de algunos PP. de la Compañía de Jesús sobre los sucesos de la Monarquía entre los años 1634 y 1648», I, pp. 641-642, en Memorial histórico español, XIII (Madrid, 1861). En la misma colección (Memorial... XIV, Madrid, 1862), II, p. 26, más detalles.

32 «Entremés famoso: Los Mariones», Colección de entremeses, loas, bailes, jácaras $y$ mogigangas desde fines del siglo XVI, a mediados del XVIII, I, 2, N.B.A.E., XVIII (Madrid, 1911), pp. $595-598$ (n." 258).

33 Solón, I, 3-4. 
cuando ven que sus parientes mayores se hacen viejos y están débiles y enfermos los abandonan a la muerte.

Por otra parte, hay conceptos que influyen de modo decisivo en la idea de lo que es crimen o no, que también, en apariencia (o según nuestro criterio al menos), no son determinantes y que, sin embargo, lo han sido. Puede subrayarse, en primer lugar, el significado del espacio en relación con la consideración de lo que es o no es crimen y con el castigo del mismo. En segundo término, con el parentesco y los vínculos de sangre. En tercero, la idea de la herencia de la culpa a través de las generaciones. Veamos algún ejemplo.

La relación del concepto de crimen con un espacio determinado, es algo digno de estudio, por lo mismo que empieza por ilustrar el nexo que hay entre un tipo de Derecho y un tipo de Estado. Pero el estudio es mejor iniciarlo, como siempre, a base de datos concretos que de hipótesis generales. Ya en viejos textos de Filosofía del Derecho se trata de las teorías acerca del origen del Estado que lo hacen nacido bien de la antigua familia patriarcal, o bien de la horda violenta que se impone ${ }^{34}$.

Cuando Ortega escribió el ensayo sobre el mismo tema, es claro que se hacía eco de las ideas de Graebner al señalar la existencia de un supuesto «ciclo cultural» (el «matriarcal-agrícola»), dentro del cual las asociaciones juveniles tenían extraordinario poder coercitivo, formando clubs, que celebraban ritos secretos y controlaban al resto de la sociedad aterrorizándola, para lo que usaban también de máscaras y otros objetos amedrentadores ${ }^{35}$. Graebner sistematizó y generalizó de modo excesivo hechos que se daban en determinados ámbitos, como Melanesia, observados por autores sin espíritu generalizador. Pero el estudio de las asociaciones juveniles, con un carácter secreto, nos lleva de modo constante al hallazgo de hechos muy distintos entre sí, aunque tengan un elemento común: el de la participación del sector más joven de la sociedad, precisamente. El uso de la violencia juvenil lo han hecho todos los que han pretendido llevar a cabo «la conquista del Estado». Los jóvenes, por otra parte, constituyen el núcleo más activo de los grupos terroristas y el decisivo en todo ejército. Esto en el mundo actual. Del pasado se reciben los esquemas. También las servidumbres. Esto ocurre con asociaciones como las ya aludidas de la «Mafia» y la «Camorra». La «Mafia» es particularmente interesante porque empieza actuando en un ámbito geográfico limitado (una zona de Sicilia), luego su

34 Icilio VANNI, Filosofía del Derecho, traducción de Rafael Urbano (Madrid, s.a.), p. 166.

35 El ensayo se publicó en El espectador, VII (Madrid, 1929), pp. 121-165. Compárese con Fritz Graebner, Das Weltbild der Primitiven (Munich, 1924), pp. 37-40. 
actuación se extiende a otro lejano (los Estados Unidos), en forma mucho mayor. Sin embargo, conserva la estructura básica de tipo familiar con el vínculo de sangre como fundamento. Resulta así evidente que en una familia trasladada de Sicilia a Norteamérica un niño, nacido en este último país, pero cuyo abuelo era un mafioso conocido en el de origen, pertenecía de modo inexorable a la sociedad y el desarrollo de su vida se hallaba condicionado por esto ${ }^{36}$. La «Mafia» no es, pues, una asociación a la que se pertenece o no voluntariamente, sino una sociedad en que se nace. El mismo nombre de «onorata società» sirve para probarlo y el carácter «íntimo» se halla también reflejado en el nombre de «cosa nostra».

La fuerza asignada a la sangre ha hecho también que cuando entre dos individuos o grupos ha habido voluntad de sellar pactos inquebrantables, ha sido bebiendo sangre o intercambiándola de una forma u otra como se han realizado. Esto en muchas sociedades antiguas y modernas: unas criminales y otras no ${ }^{37}$. Por otra parte, también en ámbitos culturales muy distintos entre sí la sangre transmite la responsabilidad de crímenes llevados a cabo por antepasados remotos, llega a los descendientes en generaciones y generaciones, y esta noción ha sido algo que se encuentra en la sociedad hebrea antigua, en el mundo clásico y en las sociedades cristianas, hasta épocas recientes. Las culpas de los padres las pagarán los hijos. Hipólito, en la terrible tragedia de Eurípides, se refiere a los males que le aquejan, efecto de crímenes cometidos por antepasados remotos ${ }^{38}$. Para el espectador de la tragedia en su época esto era tan comprensible como el que las divinidades pudieran ser no sólo vengativas, sino también malvadas. En la misma obra se presenta a Afrodita vengándose del joven casto y aliado por ello con Artemis: pero en un momento a la vengadora se la denomina malvada o malhechora de modo rotundo ${ }^{39}$. El mundo de los dioses se guía por sentimientos y pasiones de tipo humano: podríamos decir, parodiando a Nietzsche, «Menschliches, Allzumenschliches». Pero dejemos esto. Dejemos también el análisis de situaciones sociales que se han dado en el mundo cristiano mucho más moderno, en que una presunta falta de los antepasados

36 En los servicios de carácter policíaco de los Estados Unidos, por ejemplo, y concretamente en los relativos al tráfico de drogas, se han estudiado de modo minucioso los sistemas de parentesco de los que se dedican a aquel tráfico, según indica Luigi BARzINI, The italians (Nueva York, 1965), pp. 207-208. Desde otro punto de vista, la fuerza del parentesco se confirma por otros textos, como el de Vincent Teresa, My life in the Mafia (Londres-Glasgow, 1987), pp. 27-39 especialmente.

37 Jean-Paul Roux, Le sang. Mythes, symboles et realités (Paris, 1988), pp. 215. 218 , etc.

$38 \quad 1378-1381$.

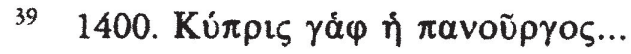


gravita sobre todos sus descendientes. Durante varios siglos han pesado sobre los descendientes de moros y judíos los estatutos de limpieza de sangre, como es sabido, acerca de los cuales hay una cuantiosa bibliografía. Recordemos algún caso distinto y más concreto de pena colectiva y hereditaria. Hasta la época de la guerra civil de España, poco más o menos, en un barrio del pueblo de Arizcun, en el valle de Baztán, llamado Bozate, vivía un grupo humano que era el de los «agotes» («agotak» en vasco) que estaba em situación clara de inferioridad: no sólo allí, sino también en tierras circundantes de la Navarra atlántica. Se les atribuían ciertos caracteres físicos y fisiológicos y se les consideraba como malditos. Aun en la iglesia ocupaban un lugar inferor. No se sabía bien por qué. La tradición decía que descendían de herejes. Otra que se agregaba a ésta, decía que sus antecesores habían sido leprosos. Ahora bien, como la lepra en un tiempo se consideró enfermedad maldita, producida por falta grave del aquejado de ella, un juicio podía ir unido al otro perfectamente. Mucho ha costado deshacer esta prevención, como costó en todo el Sudoeste de Francia, donde se señalaba la existencia de barrios de «cagots», objeto de la investigación de eruditos concienzudos ${ }^{40}$. Aquí basta con recordar el hecho como uno de los significativos al estudiar la relación de los vínculos de sangre con un espacio determinado: para ver cómo ha existido la noción de «sangre impura» a causa de supuestas faltas heredadas en relación con un espacio que también lo era. Frente a ésta se ha dado también la idea de la necesidad de mantener puro al propio ámbito en que se vive. Estrabón dice - por ejemplo- que entre los pueblos del Norte de la península ibérica, como los cántabros, a los condenados a muerte los despeñaban y a los parricidas los apedreaban "fuera de los límites» ${ }^{41}$. ¿Qué límites eran éstos? ¿Los que ocupaba la unidad estrictamente familiar o los de otra mayor? Lo segundo parece lo más probable. En todo caso, en el hecho está patente la idea de que el ámbito, el límite social propio, debe quedar limpio, puro de cierta clase de crímenes que atentaban a su esencia.

\section{A MODO DE CONCLUSIÓN}

Sin ánimo de decir algo muy nuevo, sí se puede sacar de este corto escrito una comprobación de la tesis de que el concepto social del crimen ha experimentado, en tiempos relativamente recientes y de modo progresivo,

40 Christian Delacampagne, L'invention du Racisme. Antiquité et Moyen-Age (Paris, 1983), pp. 113-139 con bibliografía abundante, pp. 350-353.

41 III, 3, 7 (155). 
los efectos de una laificación. Al enjuiciar qué es y qué no es crimen se han eliminado muchas ideas de tipo religioso. No sólo de origen cristiano, sino también más antiguas y extendidas en pueblos muy distintos. El proceso de laificación ha estado unido unas veces y otras no a interpretaciones que podríamos llamar médicas o psicopatológicas de la naturaleza de los criminales. Por otro lado, el estudio histórico cultural de distintos pueblos (incluso de un mismo pueblo a lo largo de su historia), nos hace ver que existen sensibles márgenes de variabilidad en el concepto del crimen y de la ética en general. Este relativismo no es moderno en términos absolutos, porque ya se ha visto que Protágoras reunió argumentos para defenderlo. También podemos afirmar que unido a la misma fe que tenía aquél en los efectos de la educación puede ser profesado, sin miedo a caer en lo que se llaman excesos en la conducta. Según dicta la experiencia, éstos provienen siempre de factores exteriores al mismo hombre que cae en ellos. A veces, también, al observarlos, podemos aplicar aquella idea de los criminalistas italianos respecto a la existencia de «delitos modernos» frente a otros bárbaros o primitivos, arcaizantes en suma.

En una visita a cualquier cárcel de una ciudad española, se puede advertir hoy que un tanto por ciento muy alto de los encarcelados lo están por tráfico de drogas o por delitos relacionados con el consumo de las drogas mismas. Esto no ocurría hace veinte o treinta años y es ilustrativo. El concepto del crimen se ha laificado, la imagen del criminal va cambiando y el criminal mismo actúa bajo otros intereses dominantes. La situación es como para producir la mayor perplejidad, no sólo en los criminólogos con sus distintos enfoques, sino también en los antropólogos. No hay más remedio, pues, que seguir adelante y profundizar en las averiguaciones.

Julio CARo BARoja 
Tras una breve introducción sobre el significado variable del término «Crimen», se analiza la relación multivariable que existe entre el concepto de crimen y las distintas concepciones culturales, señalando la validez de las ideas referentes a la justicia y la penalidad para la definición de las distintas culturas. El relativismo que afecta a las conductas objeto de castigo se ejemplifica en crímenes que atentan contra la religión, en la homosexualidad y el parricidio. El mismo cambio puede observarse en el significado del espacio, los vínculos de sangre y la herencia, en relación con lo que puede ser considerado crimen, o no, y su castigo.

After a brief introduction about the changeable meaning of the term "crime", the multivariable relation between the concept of crime and the different cultural conceptions is analyzed; it is also pointed out the usefulness of the ideas referred to justice and punishment for the definition of the different cultures. The relativism of punishable behaviours is exemplified by crimes related to religious regulations, homsexuality and parricide. The same variability can be perceived in the meaning of space, blood relations and heritage, with regard to what may be considered crime or not, and its punishment. 